\title{
Development of Waste Separation Practice Index among the Community of Higher Education Institutions in Malaysia
}

\author{
Yi Sean Ong \\ School of Quantitative Sciences \\ College of Arts and Science \\ Universiti Utara Malaysia \\ Malaysia
}

\author{
Nurakmal Binti Ahmad Mustaffa \\ School of Quantitative Sciences \\ College of Arts and Science \\ Universiti Utara Malaysia \\ Malaysia
}

\begin{abstract}
Lately, Malaysia is confronted with a low quality environment and the government needs to provide more efforts in alter strategies to minimize wastes. Universities bear a great responsibility in encouraging waste separation because a higher education institute campus has most of the similar characteristics as a city. This study aims to develop an index of waste separation practice among the UUM community in order to cultivate a green campus culture. With the method of systematic literature review, a conceptual model is developed and five factors that influence waste separation practice involved are identified in this study; attitude, subjective norm, perceived behavioral control, moral obligation and situational factor. Data were collected from the 1002 UUM community by using questionnaires and analysis was done by index development. The development of waste separation practice index presented in this study requires three main steps; the first involves identification of factor influence waste separation practice, the second requires weighting factor, which involves application of correlation and Hellwig method, and the final involves building of waste separation practice index using linear combination method. The result of index development displays that students are more dedicated to waste separation practice compared to academic lecturers and administrative staffs.
\end{abstract}

Keywords:- Environment; Higher education; Waste separation practice; Index; Hellwig method; Linear combination method.

\section{INTRODUCTION}

The management of municipal solid waste disposal has grabbed worldwide concern, especially in high population countries, like China, India and Japan [1]. Malaysia is also concern with waste disposal as waste generation is in the accelerating flow [2] as a result of the rapid growth of the economy due to the acceleration of the population, thus it has increased the demand for living standards among the public. At the same time, it becomes a challenge as the amount of municipal solid waste also escalates [3]. In 2013, Malaysia has recorded a total amount of waste with about 33000 tons per day [4]. It forced the government to spend a huge amount of money to process discarded substances. In 2017, the government was spent nearly RM800 million in waste management [5].

Nevertheless, Malaysia is confronted with a lowquality environment as a result of issues in handling solid wastes [6],[7]. Waste should be sorted at the first step before being disposed or recycled [8]-[9]. It can be segregated to different categories, such as paper, glass and plastics according to the different colors of bins. However, in our daily life, the activity of waste separation may be difficult to be practiced as this activity is affected by several factors. One of the most significant reasons that contribute to the low-quality environment is the unscientific and lack of the municipal solid waste segregation practice [10]. This is because the level of awareness to reduce waste among Malaysian is still low [11] where only fewer people are executing good behavior in managing their waste [12]. Due to this reason, the Malaysian government has introduced some related campaigns and programs related to waste separation, such as recycling programs and implement the facilities with the capability of handling solid waste. This is because waste sorting is a movement to cut down the dump and encourage recycling practice among people [2],[13]. A previous research exhibits that waste management usually depends on the behavioral conduct. This implies that human behavior plays a critical role in conducting waste separation. In conjunction with this, it is essential to figure out the factors that influence people to perform waste segregation and thus promote the public's intention to carry out waste separation [14]-[16].

Universities should also bear a great responsibility in encouraging the waste separation. This is because a higher education institute campus has most of the similar characteristics as a city [17]. The data of Graduates Statistics 2018 has recorded that there were nearly 5 million persons who graduated in Malaysia [18]. Previous research [19] stated that a green campus is a higher education institution that is fully or partially engaged in environmentally friendly attitudes and behavior in order to minimize the negative effect on the surrounding area. Thus, it is important to encourage sustainability in the university to reduce discarded items. The encouragement of green awareness to staff and students could help to cultivate a green campus culture. 
Most of the previous research conducted under the waste separation research area is mainly focused on determining the factors that influence waste separation intention. However, none of the research has developed the index of waste separation practice among the community of Higher education institutions. Therefore, this study aims to develop an index of waste separation practice among the higher education institution community in order to cultivate a green campus culture. The outcome of this research enabled a new operational insight on how to measure waste separation practice. The successful development of waste separation practice index could measure the likeliness of the community to practice waste separation in their daily life activities.

\section{LITERATURE REVIEW}

In general, waste separation refers to the segregation of waste according to its respective composition. According to [20], there are six main aspects of managing the municipal solid waste. These aspects are waste generation, waste handling at source, collection, transport, processing and transformation, and disposal in sequence. According to [21], waste sorting is an essential way to diminish the amount of waste and reduce environment pollution. This sequence has highlighted that the important of sorting the waste and collection. This could enhance the quality and quantity of waste before it undergoes the next steps and thus the waste can be disposed of with the most appropriate approach. Waste sorting is typically imperative to the health of human beings and the environment. This is because there is an extensive kind of waste globally and some of the wastes contain a hazardous and corrosive element which will result in pollution. The environment pollution includes air, water and land could bring a negative effect on human health. Thus, most of the developed countries have put much effort into sorting solid waste [22].

Attitude refers to the casual factors that define an individual's perception of a particular behavior [23]. It expressed a person's expectation of the favorable or unfavorable consequences to practice the action [24]. Previous research [25] defines attitude as the potential of young people's to perform the behavior of waste separation. It refers to the favorable and unfavorable viewpoints of an individual to execute the behavior. This is because human practice is normally performed according to their opinion of possible outcomes [26]. In other words, an individual would perceive higher intention to recycle if the person noticed that recycling could benefits them in certain ways. Next, according to [27], subjective norm expressed that the willingness of an individual to perform a certain behavior is affected by social pressure. An individual would probably have the intention to perform waste separation if their important referent has the idea that they should execute the behavior. These important references are normally comprised of family members, peers, and neighborhood. These individuals and groups always has a positive effect on waste separation intention as they are close to the person. A person is more likely to practice waste separation if they notice their friends, family and neighbors are participated [28]. Besides that, [29] explained that perceived behavioral control refers to the individual's opinions of the capability to perform the waste separation. Previous study [25] added that a person carried out the waste separation practice according to their self-confidence in completing the task. It indicates the perception of the easy or difficult of a person to perform a behavior [30].

According to [31], moral obligation revealed an individual's viewpoint of moral rightness to conduct a particular practice. A prior study [32] added that moral obligations and the opinions of performance outcomes could determine the waste separation intention of the public. For instance, it comprised of the young people's assumption in terms of their duties and obligation to perform waste separation [25], [33]-[34]. Moral obligation explains the personal norms of a person on the appropriate or correct way to react [35]. In addition, situational factor is one of the key determinants of waste separation practice. According to [26], situational factors is the factor that may encourage or restrict people from a particular behavior. Some authors have the same viewpoint as situational factors refers to some selective conditions. Time, space and cooperation from family members and friends are the aspects that affect the waste separation practice [26], [36][37]. Previous studies [29], [38] added that although some residents intend to practice waste separation, however, the absence of those facilities become the barrier to perform waste separation.

Despite there are much benefits from waste separation, it is well understood that waste separation practice depends on the effort of an individual to sort their waste. This practice is mostly depending on the aforementioned factors found in previous studies. From figure 1, five factors took into account; attitude, subjective norm, perceived behavioral control, moral obligation and situational factors were used to construct this conceptual framework.

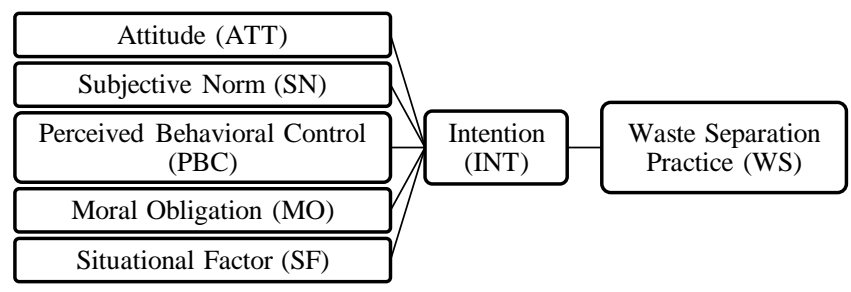

Fig 1:- Conceptual Framework

\section{METHODOLOGY}

This study was conducted in the UUM Sintok campus and the targeted respondents were UUM Community, covering the full-time undergraduate and postgraduate students, the academic lecturers and administrative staffs. In terms of research process, there were four phases of research activities involved. 
The first phase of the research process was information collection. It was performed to figure out the common factors that influence the public's intention in waste segregation. This was normally done by referring to some articles journal on to the determinants of waste separation intention and practice. It was commonly known as systematic literature review. By using the information from the first phase, a research conceptual model was developed as clarified in Figure 1. The questionnaire was used to collect the data for analysis and this questionnaire was tailored by referring to previous related studies and professional literature. The constructed questionnaire consists of three main parts with 48 questions in total. The first part of the questionnaire collected the data related to demographics and the second part of the questionnaire comprised of the five factors with their respective items. Each of the factors was constructed with a total of four to eight items of the statement. The third part of the questionnaire consists of two main groups, which are the items for the variables of intention and waste separation practice. The second and third part of the questionnaires were constructed with 7 points of Likert scale. This implied that the range of " 1 " to " 7 " is "strongly disagree" to "strongly agree", respectively. The 7 points of Likert scale was applied since the reliability could be optimized with seven response categories [39].

In this study, the respondents targeted are the UUM community which includes the academic lecturers, academic staffs and students. The questionnaire was prepared in both online and offline forms. The online questionnaire was prepared in terms of google form and the link of the google form was shared with the targeted respondents through email and WhatsApp. Meanwhile, the offline form of a questionnaire was prepared in paper form and was distributed around the UUM Sintok Campus. A timespan of five weeks was used in the phase of data collection. There were a total of 1002 respondents took part in the survey and all the responses were adopted in the analysis. This includes 294 academic lecturers, 324 administrative staff and 384 students.

An index development was the method adopted for the analysis. The development of an index has three steps which are standardizing the data, determining the weight for each factor, and developing the index.

In data standardization, the criteria and alternative were identified in the first step. The criteria refer to each factors while the alternative refers to the responses of each respondent in the study. The data collected were recorded in the form of a decision matrix in order to facilitate the presentation of mathematical concepts and calculations. The matrix was represented as $X$ in terms of $m \times n$ where $m$ and $n$ were the numbers of rows and columns of the matrix. The matrix implied that $n$ criteria were being evaluated according to the $m$ alternatives. The alternative was denoted as $A_{i}$ where $i=1,2, \ldots, m$ and the criteria $\mathrm{j}$ was denoted as $K_{j}$ where $j=1,2, \ldots ., n$. The performance of the evaluation element for alternative $i$ to criteria $j$ was denoted as $X_{i j}$. The standardization of data was computed using the formula as follows:

$Z_{i j}=\frac{x_{i j}-\min \left(x_{i j}\right)}{\max \left(x_{i j}\right)-\min \left(x_{i j}\right)}$

By using the formula, both of the maximum value and minimum value were took into account simultaneously. The standardized value was the fraction of the observation distance from the minimum value to the observation range [40].

Then, the weight for each factor were determined. The weighted score can be built in various ways depending on the nature of the problem and the available of the data. Two methods can be used to build a weighted score. One of them is by utilizing the concept of entropy, which is widely used in the communication theory [41]. Another method is by considering the size of the correlation between the factor. This is also known as Hellwig method [42]. The appropriate weights should be proportional to the correlation coefficient [40]. The formula used to compute the weighted value was outlined as follow:

$w_{j}=\frac{r_{j}}{\sum r_{j}}$

Under this study, the latter method proposed by [40] was used to calculate the weighted score. Based on the calculated weighted score, the Index is developed. One way to develop the Index is by using a composite index of multiple criteria. This involves the process of combining a set of values into a single value [43]. In this study, the method of linear combination is used, which capable of determining the ranking of preferences. The composite score for option $i$ is equal to:

$y_{i}=w_{1} z_{i 1}+w_{2} z_{i 2}+\cdots+w_{k} z_{i k}$

where y denotes value of indices, w denotes weighted score and $\mathrm{z}$ denotes standardized value

From this model, we were expecting to know the index of waste separation practice among the UUM Community where it can measure whether the UUM Community was actively involved in waste separation practice or vice versa.

\section{DATA ANALYSIS AND FINDINGS}

This section displays the result and findings of the index development. This includes the discussion on results of the correlation test, weights computation and indices.

Table 1 showed the correlation between the factors that influence waste separation intention and practice among the UUM community. The correlation indicated that all the factors have positive relationships. All the correlations of the factors were included in the weighting criteria. 


\begin{tabular}{|c|c|c|c|c|c|}
\hline & ATT & SN & PBC & MO & SF \\
\hline ATT & 1 & 0.039 & 0.134 & 0.019 & 0.067 \\
\hline SN & 0.039 & 1 & 0.106 & 0.16 & 0.315 \\
\hline PBC & 0.134 & 0.106 & 1 & 0.091 & 0.079 \\
\hline MO & 0.019 & 0.16 & 0.091 & 1 & 0.141 \\
\hline SF & 0.067 & 0.315 & 0.079 & 0.141 & 1 \\
\hline
\end{tabular}

Table 1:- Correlation Test among Factors

The result of the weighted value for each factor were shown in Table 2. With the computed weighted value, ranking are made among the five factors in which subjective norm was rank first, and followed by the situational factor, moral obligation, perceived behavioral control and attitude in ascending ranking sequence. Based on the ranking of the factors, subjective norm acts as the most important factor that affects the waste separation practice among the UUM community. This is supported by the findings of previous research about the key beliefs underlying pro-environmental behavior in high-school students which mentioned that subjective norm is excellently fit in predicted behavior [44]. It is then followed by the situational factor. This implies that the number of UUM community who involve in waste separation practice would increase if complete facilities are provided. The result is supported by a previous study that revealed that an important attribute to encourage waste separation on campus is to ensure that the community can access the recycling bins in a short distance. The limited access to recycling bins restricts waste separation behavior [45]. Previous research [46] added that the proximity of recycling bins has a great influence on recycling behavior as it encourages people to participate in waste separation behavior.

\begin{tabular}{|c|c|c|c|}
\hline Criteria & Initial value, $r_{i}$ & Weighted value, $w_{j}$ & Ranking \\
\hline SN & 1.620 & 0.2219 & 1 \\
\hline SF & 1.602 & 0.2194 & 2 \\
\hline MO & 1.411 & 0.1932 & 3 \\
\hline PBC & 1.410 & 0.1931 & 4 \\
\hline ATT & 1.259 & 0.1724 & 5 \\
\hline & & $\sum w_{j}=1.000$ & \\
\hline
\end{tabular}

Table 2:- Initial value, weighted value and ranking for factors influencing waste separation intention and practice among UUM community

With the weighted value, the index of waste separation practice was developed to each respondent by using the formula of index development. After calculation, the respondents were being sorted with the value of the index from high to low. Figure 2 shows the comparison of respondents' strata of the first 100 respondents and the last 100 respondents according to the index sequenced. In the group of first 100 respondents, students have made up the largest portion with 51 respondents out of the three strata. This indicated that students were more active in terms of waste separation practice compared to academic lecturers and staff. While, in the next group with the last 100 respondents from the index sequenced, academic lecturers have occupied the largest portion with 55 respondents. This

implied that academic lecturers were less practice in waste separation compared to students. In summary, the index of waste separation practice has been successfully developed, whereby students made up the larger portion of the UUM community who are actively involved in waste separation activity.

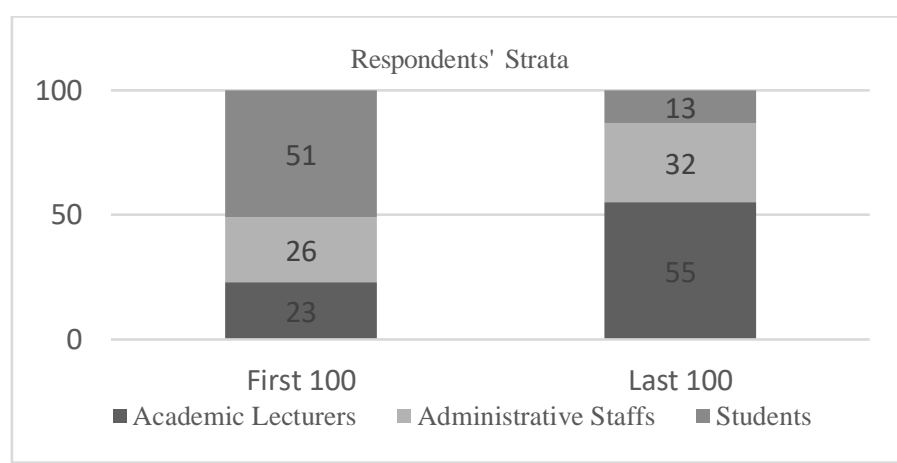

Fig 2:- Respondents' Strata

\section{CONCLUSION}

In this study, five factors such as attitude, subjective norm, perceived behavioral control, moral obligation and situational factors are involved. Also, intention and attitude of practicing the waste separation practice are encountered as dependent variables. The index developed illustrates that students are more active in waste separation practice compared to administrative staffs and academic lecturers. As a suggestion, the university should provide more waste separating facilities to encourage administrative staffs and academic lecturers to practice waste separation. For instance, the waste separation bins should place in a reachable distance such as each block and each level of the building in the university.

There is a limitation that existed. The materials focused on waste separation are not well stated in this study. Also, the questions in the survey do not specified the type of waste being separated. As an example, the researcher can ask about the attitude towards the waste separation practice with particular material such as paper, can or plastic. This tends to help the study to obtain a more significant result. Some alternative can be considered to investigate the problem related to waste separation practice. It is suggested to involved a wider range of variables in the study. Some of the variables such as personal characteristics and financial incentive could be included as the extend of the TPB model. These efforts would help to increase the power of prediction and understanding the intention of waste separation practice.

\section{ACKNOWLEDGEMENT}

The authors of this study would like to thank the School of Quantitative Sciences for providing the research facilities. 


\section{REFERENCES}

[1]. Frederiks, E. R., Stenner, K., \& Hobman, E. V. (2015). Household energy use: Applying behavioural economics to understand consumer decision-making and behaviour. Renewable and Sustainable Energy Reviews, 41, 1385-1394.

[2]. Badgie, D. (2010). Solid Waste Management System in the Kanifing Municipal Council Area, The Gambia (Doctoral dissertation, Universiti Putra Malaysia).

[3]. Al-Khatib, I. A., Monou, M., Zahra, A. S. F. A., Shaheen, H. Q., \& Kassinos, D. (2010). Solid waste characterization, quantification and management practices in developing countries. A case study: Nablus district-Palestine. Journal of environmental management, 91(5), 1131-1138.

[4]. Bernama (2014, Jan 20). 30000 metric tonnes of rubbish discarded daily. Available at http://english.astroawani.com/malaysia-news/30-000metric-tonnes-rubbish-discarded-daily-28577

[5]. Department of Statistics Malaysia (2019a, May 31). Survey of Environmental Protection Expenditure 2018. Available at https://www.dosm.gov.my/v1/index.php?r=column/ct hemeByCat\&cat=154\&bul_id=L1BTVXhaaEFPeER Dc2Y1K3JLWVdMQT09\&menu_id=NWVEZGhEV1 NMeitaMHNzK2htRU05dz09

[6]. Chin, Y. S. J., De Pretto, L., Thuppil, V., \& Ashfold, M. J. (2019). Public awareness and support for environmental protection-A focus on air pollution in peninsular Malaysia. PloS one, 14(3), e0212206.

[7]. Khajuria, A., Yamamoto, Y., \& Morioka, T. (2010). Estimation of municipal solid waste generation and landfill area in Asian developing countries. Journal of Environmental Biology, 31(5), 649-654.

[8]. Ramayah, T., \& Rahbar, E. (2013). Greening the environment through recycling: an empirical study. Management of Environmental Quality: An International Journal.

[9]. Boldero, J. (1995). The Prediction of Household Recycling of Newspapers: The Role of Attitudes, Intentions, and Situational Factors 1. Journal of Applied Social Psychology, 25(5), 440-462.

[10]. Firdaus, G., \& Ahmad, A. (2010). Management of urban solid waste pollution in developing countries.

[11]. The Star Online. (2017, Aug 20). Low awareness on recycling among Malaysians. Available ata https://www.thestar.com.my/news/nation/2017/08/20/1 ow-awareness-on-recycling-among-malaysians/

[12]. Moh, Y. C., \& Manaf, L. A. (2014). Overview of household solid waste recycling policy status and challenges in Malaysia. Resources, Conservation and Recycling, 82, 50-61.

[13]. Poon, C. S., Ann, T. W., \& Ng, L. H. (2001). On-site sorting of construction and demolition waste in Hong Kong. Resources, conservation and recycling, 32(2), 157-172.

[14]. Low, S. T. (2012). Factors Affecting Energy Conservation Behaviour of Students in Malaysian
Universities (Doctoral dissertation, Universiti Teknologi Malaysia).

[15]. Wang, Z., Zhang, B., Yin, J., \& Zhang, Y. (2011). Determinants and policy implications for household electricity-saving behaviour: Evidence from Beijing, China. Energy Policy, 39(6), 3550-3557.

[16]. Webb, T., Joseph, J., Yardley, L., \& Michie, S. (2010). Using the internet to promote health behavior change: a systematic review and meta-analysis of the impact of theoretical basis, use of behavior change techniques, and mode of delivery on efficacy. Journal of medical Internet research, 12(1), e4.

[17]. Alshuwaikhat, H. M., \& Abubakar, I. (2008). An integrated approach to achieving campus sustainability: assessment of the current campus environmental management practices. Journal of cleaner production, 16(16), 1777-1785.

[18]. Department of Statistics Malaysia. (2019b, Dec 13). Graduates Statistics 2018. Available at https://www.dosm.gov.my/v1/index.php?r=column/ct hemeByCat\&cat=476\&bul_id=cDJkZjM5b2hjdjJZM DlvNDlueU54Zz09\&menu_id=Tm8zcnRjdVRNWW1 pWjRlbmtlaDk1UT09

[19]. Velazquez, L., Munguia, N., Platt, A., \& Taddei, J. (2006). Sustainable university: what can be the matter?. Journal of Cleaner Production, 14(9-11), 810-819.

[20]. Tchobanoglous, G. and Kreith, F. (2002). Handbook of Solid Waste Management, 2nd ed., McGraw-Hill, USA.

[21]. Zeng, C., Niu, D., \& Zhao, Y. 2015. A comprehensive overview of rural solid waste management in China. Frontiers of Environmental Science \& Engineering, 9(6), 949-961.

[22]. Zhang, H., Liu, J., Wen, Z. G., \& Chen, Y. X. (2017). College students' municipal solid waste source separation behavior and its influential factors: A case study in Beijing, China. Journal of Cleaner Production, 164, 444-454.

[23]. Greaves, M., Zibarras, L. D., \& Stride, C. (2013). Using the theory of planned behavior to explore environmental behavioral intentions in the workplace. Journal of Environmental Psychology, 34, 109-120.

[24]. Lim, Y. M., Yap, C. S., \& Lee, T. H. (2011). Intention to shop online: A study of Malaysian baby boomers. African Journal of Business Management, 5(5), 1711.

[25]. Shen, L., Si, H., Yu, L., \& Si, H. (2019). Factors influencing young people's intention toward municipal solid waste sorting. International journal of environmental research and public health, 16(10), 1708.

[26]. Ghani, W. A. W. A. K., Rusli, I. F., Biak, D. R. A., \& Idris, A. (2013). An application of the theory of planned behaviour to study the influencing factors of participation in source separation of food waste. Waste management, 33(5), 1276-1281.

[27]. Ayob, S. F., Sheau-Ting, L., Jalil, R. A., \& Chin, H. C. (2017). Key determinants of waste separation intention: empirical application of TPB. Facilities. 
[28]. Bezzina, F. H., \& Dimech, S. (2011). Investigating the determinants of recycling behaviour in Malta. Management of Environmental Quality: An International Journal.

[29]. Zhang, D., Huang, G., Yin, X., \& Gong, Q. (2015). Residents' waste separation behaviors at the source: Using SEM with the theory of planned behavior in Guangzhou, China. International journal of environmental research and public health, 12(8), 9475-9491.

[30]. Ajzen, I. 1991. The theory of planned behavior. Organizational behavior and human decision processes, 50(2), 179-211.

[31]. Xu, L., Ling, M., Lu, Y., \& Shen, M. (2017). Understanding household waste separation behaviour: Testing the roles of moral, past experience, and perceived policy effectiveness within the theory of planned behaviour. Sustainability, 9(4), 625.

[32]. Wang, Z., Dong, X., \& Yin, J. (2018). Antecedents of urban residents' separate collection intentions for household solid waste and their willingness to pay: Evidence from China. Journal of Cleaner Production, 173, 256-264.

[33]. Yuan, Y., Nomura, H., Takahashi, Y., \& Yabe, M. (2016). Model of Chinese household kitchen waste separation behavior: A case study in Beijing city. Sustainability, 8(10), 1083.

[34]. Nguyen, T. T. P., Zhu, D., \& Le, N. P. (2015). Factors influencing waste separation intention of residential households in a developing country: Evidence from Hanoi, Vietnam. Habitat International, 48, 169-176.

[35]. Philippsen, Y. (2015). Factors influencing students' intention to recycle. School of Management and Governance: Master's Thesis.

[36]. Heidari, A., Kolahi, M., Behravesh, N., Ghorbanyon, M., Ehsanmansh, F., Hashemolhosini, N., \& Zanganeh, F. (2018). Youth and sustainable waste management: a SEM approach and extended theory of planned behavior. Journal of Material Cycles and Waste Management, 20(4), 2041-2053.

[37]. Ma, J., Hipel, K. W., Hanson, M. L., Cai, X., \& Liu, Y. (2018). An analysis of influencing factors on municipal solid waste source-separated collection behavior in Guilin, China by Using the Theory of Planned Behavior. Sustainable cities and society, 37, 336-343.

[38]. Nomura, H., Takahashi, Y., \& Yabe, M. (2017). Psychological driving forces behind households' behaviors toward municipal organic waste separation at source in Vietnam: a structural equation modeling approach. Journal of Material Cycles and Waste Management, 19(3), 1052-1060.

[39]. Colman, A. M., Norris, C. E., \& Preston, C. C. (1997). Comparing rating scales of different lengths: Equivalence of scores from 5-point and 7-point scales. Psychological Reports, 80(2), 355-362.

[40]. Jemain, A. A. (2004). Penentuan wajaran dalam pembinaan indeks pelbagai kriteria. Matematika, 20, 77-85.
[41]. Shannon, C. E., \& Weaver, W. (1949). The mathematical theory of communication, 117 pp. Urbana: University of Illinois Press.

[42]. Hellwig, Z. (1968). On the optimal choice of predictors. Study VI. Toward a system of quantitative indicators of components of human resources development. UNESCO, Paris, 1-23.

[43]. Zulkifli, M., Ismail, N., Razali, A. M., \& Kasim, M. M. (2014), June. Development of car theft crime index in peninsular Malaysia. In AIP Conference Proceedings (Vol. 1602, No. 1, pp. 975-982). American Institute of Physics.

[44]. De Leeuw, A., Valois, P., Ajzen, I., \& Schmidt, P. (2015). Using the theory of planned behavior to identify key beliefs underlying pro-environmental behavior in high-school students: Implications for educational interventions. Journal of environmental psychology, 42, 128-138.

[45]. Sheau-Ting, L., Sin-Yee, T., \& Weng-Wai, C. (2016). Preferred attributes of waste separation behaviour: An empirical study. Procedia Engineering, 145, 738-745.

[46]. Malakahmad, D., Amirhossein, D., Nasir, C. M., Za'im Zaki, M., Kutty, S. R. M., \& Isa, M. H. (2010). Solid waste characterization and recycling potential for university technology petronas academic buildings. American Journal of Environmental Sciences, 6(5), 422-427. 